\title{
Aspectos da prática pedagógica considerados na elaboração de um caso multimídia para formação de professores que ensinam Matemática
}

\section{Aspects of pedagogical practice considered in the elaboration of a multimedia case for training of teachers who teach mathematics}

\author{
Paulo Henrique Rodrigues ${ }^{1}$. Márcia Cristina de Costa Trindade Cyrino ${ }^{1}$
}

\begin{abstract}
Resumo: Este artigo tem como objetivo discutir aspectos da prática pedagógica, considerados por um grupo de estudos e pesquisa na elaboração de um caso multimídia a ser utilizado na formação de professores que ensinam Matemática (FPEM). Foi realizada uma pesquisa qualitativa de cunho interpretativo, cuja análise das informações incidiu sobre as negociações de significados e reflexões compartilhadas pelos membros desse grupo, na elaboração de um caso multimídia, em três empreendimentos: discussão de artigo e elaboração de um framework, discussão de casos multimídia portugueses e estruturação do caso multimídia “Os colares". Para apresentação dos resultados, foi associado o conjunto de aspectos da prática pedagógica, mobilizados por tal grupo, no planejamento e na prática da professora protagonista do caso multimídia "Os colares". Esses aspectos revelam as expectativas do grupo de a exploração de casos multimídia, na FPEM, ser uma oportunidade de construção e desenvolvimento da identidade profissional de (futuros) professores que ensinam Matemática.
\end{abstract}

Palavras-chave: Educação matemática. Formação de professores. Ensino de matemática. Prática pedagógica. Multimídia.

\begin{abstract}
This article aims to discuss aspects of pedagogical practice considered by a research group in the development of a multimedia case to be used in mathematics teacher education (MTE). Qualitative research, of an interpretative character, was carried out, and analysis of the information focused on the negotiations of meanings and reflections shared by the members of this group, in the elaboration of a multimedia case, in three projects: paper discussion and elaboration of a framework, discussion of Portuguese multimedia cases and the structuring of a multimedia case "The collars". For presentation of the results, we associated the set of aspects of teaching practice mobilized by the group based on the planning and practice of a teacher protagonist of the multimedia case "The Collars". These aspects reveal the expectations of the group and the exploitation of multimedia cases in the MTE, as an opportunity to build and develop the professional identity of (future) teachers who teach mathematics.
\end{abstract}

Keywords: Mathematics education. Teacher training. Mathematics teaching. Pedagogical practice. Multimedia.

\footnotetext{
${ }^{1}$ Universidade Estadual de Londrina (UEL), Departamento de Matemática, Londrina, PR, Brasil. E-mail: <paulohr_91@yahoo.com.br>.
} 


\section{Introdução}

O "Grupo de Estudos e Pesquisa sobre Formação de Professores que Ensinam Matemática" (GEPEFOPEM) defende a constituição de grupos de estudos, com a intencionalidade de que esses se constituam como Comunidades de Prática² (CYRINO, 2016b; CYRINO; CALDEIRA, 2011; GARCIA, 2014; NAGY; CYRINO, 2014), a fim de aprimorar o processo da docência. Desse modo, o Gepefobem tem investigado, em confronto, fatores que interferem no desenvolvimento profissional de professores que ensinam Matemática, em contextos de formação inicial e continuada distintos, quando participantes dessas Comunidades de Prática e quando o formador assume o papel de único protagonista do seu processo de formação.

Nas investigações dos contextos de formação, analisados pelo Gepefopem, foram identificados elementos que oferecem oportunidades de aprendizagem aos envolvidos e estudadas estratégias para fomentar essas aprendizagens. Dentre essas estratégias, a análise ou a exploração de casos multimídia foi pensada como possível ferramenta que pode contribuir para o desenvolvimento profissional de professores que ensinam Matemática.

Nesse sentido, por meio de um projeto de cooperação entre a Universidade Estadual de Londrina (UEL) e a Universidade de Lisboa (UL), o Gepefopem já produziu três casos multimídia a serem utilizados na formação de professores que ensinam Matemática. Esses casos multimídia estão em uma plataforma online e contemplam vídeos com episódios de sala de aula, plano de aula do professor, áudio de entrevistas realizadas com o professor (antes e após a aula), produção escrita dos alunos, questões para reflexão, textos de apoio, dentre outros (CYRINO, 2016a). Os casos multimídia elaborados até o momento estão relacionados às ações desencadeadas em uma sala de aula em que o professor regente é experiente na perspectiva do Ensino Exploratório.

O Ensino Exploratório ${ }^{3}$ é uma abordagem de ensino que trabalha com tarefas desafiadoras e apelativas que visam sistematizar uma ideia, conceito ou conteúdo matemático, de acordo com a intenção do professor (CANAVARRO, 2011; CYRINO; OLIVEIRA, 2016; OLIVEIRA; MENEZES; CANAVARRO, 2013; STEIN et al., 2008). Uma aula, nesse enfoque, é organizada em quatro fases, nomeadamente: proposição e apresentação da tarefa, desenvolvimento da tarefa, discussão coletiva e sistematização. Na primeira fase, é feita a proposição e a apresentação da tarefa com leitura, esclarecimento de dúvidas e definição da gestão da aula (dinâmica e tempo). No desenvolvimento da tarefa, segunda fase, há preocupação com o modo com que os alunos se engajam na resolução da tarefa, seus conhecimentos prévios e possíveis

\footnotetext{
${ }^{2}$ Segundo Wenger, McDermott e Snyder (2002), Comunidades de Prática são grupos de pessoas que compartilham uma preocupação, um conjunto de problemas, ou uma paixão sobre um tópico, e que aprofundam seu conhecimento e experiência nessa área, interagindo em uma base contínua. Em uma Comunidade de Prática deve haver um compromisso mútuo dos participantes na procura de um empreendimento articulado que envolva a preocupação com a aprendizagem de todos os seus membros e um compartilhar de seus repertórios (CYRINO, 2009).

${ }^{3} \mathrm{O}$ Ensino Exploratório nas aulas de Matemática tem como orientações gerais quatro aspectos considerados fundamentais nas abordagens Inquiry-based Mathematics Education (IBME), nomeadamente: inquiry, colaboração, comunicação e reflexão (CYRINO; OLIVEIRA, 2016).
} 
Aspectos da prática pedagógica considerados na elaboração de um caso ...

intervenções do professor para promover interações entre os alunos. Na terceira fase, são discutidas, com toda a turma, as resoluções dos alunos, escolhidas e sequenciadas pelo professor. Nessa fase, o professor estabelece relações entre as diferentes resoluções de acordo com seus objetivos de ensino. $\mathrm{Na}$ sistematização, quarta fase, o professor, a partir das relações instituídas na fase anterior, sistematiza a ideia, conceito ou conteúdo pretendido (CANAVARRO, 2011; CYRINO; OLIVEIRA, 2016; OLIVEIRA; MENEZES; CANAVARRO, 2013).

Discutimos, aqui, neste artigo, os aspectos da prática pedagógica de uma professora que ensina Matemática, considerados pelo Gepefopem na elaboração do caso multimídia "Os colares". Para tanto, situamos teoricamente a utilização de multimídias e tecnologias na formação de professores que ensinam Matemática, seguido dos procedimentos metodológicos e da explicitação de cada um dos empreendimentos, cuja conjugação nos permitiu elencar tais aspectos e considerar o caso multimídia como uma oportunidade de desenvolvimento profissional de professores que ensinam Matemática.

\section{A utilização de multimídias e tecnologias na formação de professores que ensinam Matemática}

Neste trabalho, assumimos os termos "mídia" e "tecnologia" em uma relação de dependência (BATES, 2005). De acordo com esse autor, mídia refere-se à descrição de formas genéricas de comunicação, associadas a modos particulares de representação de conhecimentos, enquanto tecnologias são ferramentas que possibilitam que as informações das mídias sejam apresentadas. Há cinco tipos de mídias (face a face, texto, áudio, vídeo, multimídia digital) e cada uma delas possui características próprias. Para cada uma dessas mídias, existem várias tecnologias que as representam. Por exemplo, a televisão é uma tecnologia que possibilita que as informações da mídia vídeo sejam apresentadas.

Uma das mídias, especificamente a multimídia digital, incorpora elementos de texto, áudio e vídeo, além de possuir características próprias como a animação e a interatividade. É justamente nessa direção que assumimos o termo "multimídia": a incorporação, em um mesmo processo, de várias mídias.

Nos últimos anos, alguns pesquisadores têm investigado a utilização de multimídias e tecnologias na formação de professores em contextos de análise de ensino (ALSAWAIE; ALGHAZO, 2010; OLIVEIRA; CYRINO, 2013; RODRIGUES et al., 2014; SANTAGATA; GUARINO, 2011; STEIN; SMITH, 2009; VAN ES; SHERIN, 2002, 2008).

Rodrigues et al. (2014) analisaram pesquisas brasileiras (dissertações e teses) que tinham como objetivo estudar em que contextos a mídia vídeo era utilizada na formação de professores que ensinam Matemática. Como resultado, concluíram que, embora muitos trabalhos reconheçam a mídia vídeo e outras mídias e tecnologias como potenciais em contextos de formação de professores que ensinam Matemática, nenhum deles assumiu essa temática como foco principal de investigação.

Em âmbito internacional, alguns trabalhos investigaram as potencialidades do uso da mídia vídeo, articulada a outras mídias, na formação de professores, e o reconhecimento e a interpretação de interações em sala de aula (ALSAWAIE; ALGHAZO, 2010; OLIVEIRA; CYRINO, 2013; SANTAGATA; GUARINO, 2011; STEIN; SMITH, 2009; VAN ES; SHERIN, 2002 , 2008). Os resultados desses trabalhos mostram que os sujeitos, de modo geral, apresen- 
taram indícios de aprendizagens a respeito da análise de ensino a partir de uma dinâmica de discussão coletiva em torno de vídeos e de ações em sala de aula, por vezes dos próprios sujeitos que participaram das discussões.

Van Es e Sherin (2002) realizaram uma pesquisa com um grupo de futuros professores de Matemática e Ciências com o objetivo de verificar se os sujeitos aí envolvidos aprenderam a reconhecer e interpretar interações em sala de aula. Os membros desse grupo se organizaram em encontros para analisar práticas em sala de aula registradas em vídeo. Em alguns momentos, analisavam suas próprias práticas e, em outros, as de professores já experientes. Esses autores apontam três dimensões do que consiste reconhecer e interpretar interações em sala de aula, quais sejam:

- identificar o que é importante ou digno de nota em uma situação de sala de aula;

- usar o que se sabe sobre o contexto para interpretar interações em sala de aula;

- fazer conexões entre as especificidades das interações em sala de aula e os princípios mais amplos de ensino e de aprendizagem.

Van Es e Sherin (2002) salientam que, para o professor conseguir implementar práticas de ensino alternativas ${ }^{4}$, é necessário reconhecer e interpretar interações em sala de aula. Segundo eles, em práticas alternativas, os alunos possuem um papel mais ativo, e o professor, de modo geral, lida com o improviso, que demanda adequações ao ensino a partir do que acontece em sala de aula. Nesse sentido, segundo esses autores, para configurar o encaminhamento que a aula terá, o professor precisa reconhecer e interpretar aspectos específicos relacionados à sua própria prática pedagógica.

Esses mesmos estudiosos, Van Es e Sherin (2008), assumindo as três dimensões apresentadas anteriormente em 2002, realizaram uma pesquisa com professores da Educação Básica, quando participaram de um grupo de estudos que analisava vídeos, que representavam práticas de sala de aula de alguns professores participantes o grupo. Os objetivos do trabalho foram investigar mudanças dos apontamentos dos professores a partir do momento em que passaram a participar do grupo e observar indícios de aprendizagem relacionados a reconhecer e interpretar interações em sala de aula por parte deles.

Além de observar as interações nos encontros do grupo, os autores entrevistaram os professores antes e depois das participações deles nas dinâmicas estabelecidas. Nas entrevistas, também foram apresentados trechos de vídeos que se constituíram como objeto de análise dos entrevistados. Baseados em outros trabalhos, como o de Van Es e Sherin (2002), os autores estruturaram cinco agrupamentos relacionados às ações de reconhecer e de interpretar interações em sala de aula, de modo a observar a mudança dos apontamentos desses professores: (1) identificação dos atores no vídeo; (2) identificação de outros elementos no vídeo (indícios de pensamento matemático dos alunos, pedagogia, interações, gestão da aula, etc.); (3) análise da prática (análise das ações dos alunos e professor); (4) níveis dos apontamentos (gerais ou específicos); (5) natureza dos apontamentos.

\footnotetext{
${ }^{4}$ Práticas de ensino distintas das tradicionais, nas quais o professor é o único protagonista dos processos de ensino e de aprendizagem. 
Stein e Smith (2009) assinalaram que a utilização de multimídias, principalmente no que diz respeito à mídia vídeo, pode ser um elemento potencial para reflexão em contextos de formação de professores. Elas sugerem que as aulas de um professor podem ser filmadas de modo a possibilitar reflexões (individuais ou coletivas) a respeito das ações em sala de aula e do desenvolvimento profissional tanto do professor filmado (que pode refletir a respeito de sua aula), quanto de outros profissionais que analisam as filmagens (perspectiva coletiva).

Alsawaie e Alghazo (2010) apresentaram características para as três dimensões do que consiste reconhecer e interpretar interações em sala de aula (VAN ES; SHERIN, 2002). Assim, para a primeira delas - identificar o que é digno de nota em uma situação - assinalam que determinar acontecimentos relevantes em uma situação de ensino depende da imagem do que é importante no ensino de cada um. Para a segunda - usar o que se sabe sobre o contexto para interpretar interações em sala de aula - afirmam que os professores usam seus conhecimentos sobre o assunto, a pedagogia e o pensamento dos alunos para interpretar o que observam e para propor estratégias de ensino alternativas. Já para a terceira - fazer conexões entre as especificidades das interações em sala de aula e os princípios mais amplos de ensino e de aprendizagem - pontuam que ela envolve a relação dos eventos observados com conhecimentos, crenças, experiências e princípios mais amplos de ensino e de aprendizagem. A principal característica dessa terceira dimensão é pretender que os professores em formação ${ }^{5}$ estabeleçam relação entre aspectos particulares (como aspectos específicos observados nos vídeos) e aspectos mais gerais (teóricos). No contexto investigado por esses autores, por exemplo, os aspectos mais gerais (teóricos) assumidos, dizem respeito às informações apresentadas no Nacional Council of Teachers of Mathematics (2000).

Santagata e Guarino (2011) utilizaram a mídia vídeo, relacionada à análise de ações em sala de aula, em contextos de formação inicial com o objetivo de que futuros professores de Matemática constituíssem conhecimentos para analisar e refletir a respeito do ensino de Matemática, que se relacionam a: prestar atenção a elementos importantes das ações em sala de aula; raciocinar sobre esses elementos de forma integrada e propor estratégias de ensino alternativas.

Oliveira e Cyrino (2013) discutiram a utilização de multimídias na formação inicial de professores que ensinam Matemática, a partir da exploração de um caso multimídia no contexto de um curso de formação de professores na Universidade de Lisboa. As autoras buscaram discutir/compreender os conhecimentos que futuros professores de Matemática desenvolveram sobre a perspectiva do Ensino Exploratório. O caso multimídia, neste contexto, diz respeito a uma aula desenvolvida por uma professora de um $7^{\circ}$ ano do Ensino Básico nessa perspectiva de ensino. Os resultados evidenciam que a exploração do caso multimídia possibilitou que os futuros professores "desenvolvessem uma compreensão acerca de várias dimensões de uma prática de ensino exploratório, e da sua complexidade e simultaneamente começassem a perspectivar a sua futura prática profissional, antecipando desafios" (OLIVEIRA; CYRINO, 2012, p. 214). Esses casos multimídias inspiraram o caso assumido como objeto de análise neste artigo.

\footnotetext{
${ }^{5}$ A partir deste ponto, ao utilizarmos a expressão "professor em formação", estamos nos referindo tanto ao professor em formação inicial quanto ao professor em formação continuada.
} 


\section{Encaminhamento metodológico}

Realizamos uma pesquisa qualitativa de cunho interpretativo, com abordagem pautada na pesquisa-intervenção (KRAINER, 2003), a respeito da prática do Gepefopem nos anos de 2013 e 2014 na elaboração de um caso multimídia (“Os colares”) a ser utilizado na formação de professores que ensinam Matemática. Participaram do grupo investigado quatro alunos de mestrado (Helen, Laís, Merline e Paulo) e seis alunos de doutorado (Cristina, Everton, Gaspar, Loreni, Renata e Tânia) do programa de Pós-Graduação em Ensino de Ciências e Educação Matemática da Universidade Estadual de Londrina (UEL), além de seis outros pesquisadores/ participantes (Angélica, Bruno, Janaína, Loyanne e Marcia Nagy), da coordenadora do grupo (Márcia Cyrino), e da consultora do projeto (Hélia). Tais sujeitos autorizaram, por meio de um termo de consentimento livre e esclarecido, a participação nessa pesquisa, que foi aprovada pelo Comitê de Ética em Pesquisa da UEL.

Esse caso multimídia faz parte de um recurso multimídia constituído por um conjunto de casos que envolvem professores experientes em situações reais de sala de aula na Educação Básica, na perspectiva do Ensino Exploratório (CANAVARRO, 2011; CYRINO; OLIVEIRA, 2016; OLIVEIRA, MENEZES, CANAVARRO, 2013; STEIN et al., 2008). A principal intenção de cada um dos casos é possibilitar que os professores em formação (inicial e continuada) possam refletir a respeito de diferentes aspectos da prática pedagógica. Consideramos a reflexão como uma ação ativa e criteriosa de experiências, teorias, ideias, ações ou discursos que possibilitam sustentar o desenvolvimento de conclusões, novas ideias ou compreensões (CHAPMAN, 2013; DEWEY, 1997; SCHON, 2000; WELLS, 2004).

Cada caso multimídia engloba diversos materiais (mídias) que envolvem as ações de um professor em torno de uma aula: plano de aula, episódios de gravações em vídeo dessa aula, entrevistas antes e depois da aula com o professor, produção escrita dos alunos, textos, dentre outros. Nas seções e subseções que compõem cada caso, há questões desencadeadas por cada um desses diferentes materiais, as quais devem ser respondidas pelos professores em formação.

Os casos multimídia brasileiros foram inspirados nos casos produzidos em Portugal, no âmbito do projeto Práticas Profissionais dos Professores de Matemática (P3M), da Universidade de Lisboa ${ }^{7}$. A constituição de casos multimídia pelo Gepefopem no Brasil está relacionada a um projeto de cooperação entre a Universidade Estadual de Londrina (UEL) e a Universidade de Lisboa (UL), denominado "Rede de cooperação UEL/UL na elaboração e utilização de recursos multimídias na formação de professores de matemática". A intenção da proposta desse projeto foi construir casos multimídia a partir de aulas com especificidades educacionais brasileiras, tendo a colaboração da professora Hélia Oliveira, que coordenou o processo de elaboração de casos multimídia portugueses. Como tais casos possuem registros em vídeo, onde há informações de alunos da Educação Básica, da escola e da professora regente da turma, as informações e as imagens apresentadas foram autorizadas pelos sujeitos envolvidos ou pelos seus responsáveis.

\footnotetext{
${ }^{6}$ Profa. Dra. Hélia Margarida Oliveira, da Universidade de Lisboa.

${ }^{7}$ Disponível em: <http://p3m.ie.ul.pt/>. Acesso em: 27 jun. 2017.

${ }^{8}$ Esse projeto foi aprovado pelo comitê de ética de seres humanos da Universidade Estadual de Londrina. 
A aula que viabilizou a constituição do caso multimídia "Os colares" foi desenvolvida pela professora Cristina (experiente no desenvolvimento de aulas na perspectiva do Ensino Exploratório) em uma de suas turmas, nomeadamente em um $6^{\circ}$ ano do Ensino Fundamental de uma escola pública de periferia do município de Apucarana (Paraná), e envolvia o pensamento algébrico.

O caso multimídia “Os colares" é organizado em torno de cinco seções, dispostas na barra horizontal (Figura 1): (i) Introdução do Caso Multimídia; (ii) Antes da aula; (iii) A aula; (iv) Reflexão após a aula; (v) Colocar em prática.

Figura 1. Seção "antes da aula" do caso multimídia "Os colares"

\section{Caso Multimídia 1: "Os Colares"}

Introdução do Caso Multimídia Antes da aula A aula Reflexão após a aula Colocar em prática

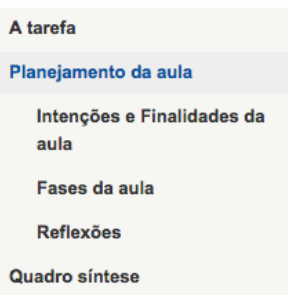

\section{Planejamento da aula}

Essa subseção é dividida em três itens relacionados às ações da professora no planejamento da aula: "Intenções e finalidades da aula", "Fases da aula" e "Reflexões". Nesses itens você terá acesso a duas diferentes fontes de informações: o vídeo com trechos da entrevista realizada com a professora antes do desenvolvimento da aula e o plano de aula. A partir das informações disponíveis, responda as questões presentes no final de cada página.

Fonte: Disponível em: <http://rmfp.uel.br/>. Acesso em: 27 jun. 2017.

Para o levantamento das informações consideradas neste artigo, no processo de elaboração deste caso multimídia, denominado "Os colares", foram considerados os áudios gravados dos encontros do Gepefopem; as gravações do hangout ${ }^{10}$, uma vez que alguns encontros aconteceram a distância; o diário de campo; e as memórias do grupo (breves relatos dos encontros). Os encontros do grupo aconteceram, usualmente, às sextas feiras, das $09 \mathrm{~h} 00$ ao $12 \mathrm{~h} 00 \mathrm{e}$ das $13 \mathrm{~h} 30$ às $16 \mathrm{~h} 00$, em 2013 e 2014.

\footnotetext{
${ }^{9}$ O caso multimídia possui o nome de "Os colares", por conta da tarefa desenvolvida em sala de aula. Mais detalhes sobre ela podem ser encontrados em Rodrigues (2015).

${ }^{10}$ Ferramenta gratuita de videoconferência do google. Disponível em: <http://www.google.com/+/learnmore/ hangouts/?hl=pt-BR>. Acesso em: 27 jun. 2017.
} 


\section{Procedimentos de análise dos dados}

Analisamos as negociações de significados ${ }^{11}$ e as reflexões compartilhadas ${ }^{12}$ nos empreendimentos combinados pelo Gepefopem no processo de elaboração do caso multimídia, quais sejam: (E1) discussão de artigo e elaboração de um framework ${ }^{13}$ (quadro de referência com ações do professor na perspectiva do Ensino Exploratório); (E2) discussão de casos multimídia portugueses, e; (E3) estruturação do caso multimídia "Os colares".

Em E1, o Gepefopem, a partir da discussão e da análise do artigo de Stein et al. (2008) e das experiências docentes dos membros do grupo, construiu um framework com possíveis ações de um professor em uma aula na perspectiva do Ensino Exploratório. No framework, foram listadas ações de um professor que pretende assumir esse referencial de ensino, quais sejam: antecipar; propor a tarefa; monitorar a resolução da tarefa; selecionar e sequenciar as resoluções para discussão; discutir as resoluções; e sistematizar as aprendizagens. Para cada uma dessas ações, foram associados alguns elementos que as compõem. A intenção é que esse quadro seja analisado pelo professor em formação na exploração do caso multimídia na seção "Após a aula".

Para exemplificar, apresentamos, no Quadro 1, um fragmento do framework, com os elementos que compõem a ação de monitorar a resolução da tarefa.

Quadro 1. Fragmento do framework

\begin{tabular}{|c|c|}
\hline Ação & Elementos que compõem as ações \\
\hline $\begin{array}{l}\text { Monitorar a } \\
\text { resolução da } \\
\text { tarefa }\end{array}$ & $\begin{array}{l}\text { - Questionar, orientar e provocar o aluno quanto à resolução da tarefa. } \\
\text { - Promover e mediar a interação entre os alunos. } \\
\text { - Manter o desafio cognitivo e a autonomia dos alunos. } \\
\text { - Solicitar justificações para as resoluções e as representações utilizadas (corretas } \\
\text { ou não). } \\
\text { - Não validar a correção das respostas dos alunos. } \\
\text { - Identificar as diferentes resoluções e representações e possíveis conexões entre } \\
\text { elas. } \\
\text { - Avaliar o potencial das diferentes resoluções para a discussão e a aprendizagem } \\
\text { dos conhecimentos matemáticos envolvidos na tarefa. } \\
\text { - Fazer anotações a respeito das resoluções que têm potencial para promover a } \\
\text { discussão e a aprendizagem dos conhecimentos matemáticos envolvidos na tarefa. }\end{array}$ \\
\hline
\end{tabular}

Fonte: Cyrino e Teixeira (2016, p. 86).

\footnotetext{
${ }^{11}$ Segundo Wenger (1998), a participação no mundo é, acima de tudo, um processo de negociação de significado. A experiência do significado não acontece do nada, tampouco é uma atividade mecânica. Quando agimos em uma prática, sempre nos ocupamos de significados. "[...] A negociação de significado supõe intervenção contínua em um processo de dar e de receber, de influenciar e de ser influenciado, assim como a intervenção de diversos fatores e de diversas perspectivas" (CYRINO; CALDEIRA, 2011, p. 378).

${ }^{12}$ Nesse trabalho, entendemos "reflexões compartilhadas" por aquilo que os sujeitos consideram legítimo dizer e dizem em empreendimentos caracterizados por constante negociação de significados.

${ }^{13}$ Cyrino e Teixeira (2016).
} 
Aspectos da prática pedagógica considerados na elaboração de um caso ...

O framework é um dos artefatos com que os professores em formação têm contato quando exploram o caso multimídia. Como o caso multimídia "Os colares" foi inspirado nos casos multimídia portugueses, os membros do Gepefopem negociaram que, para constituí-lo, um dos pontos de partida poderia ser a exploração ou a análise de alguns casos multimídia portugueses (E2). Essa etapa contou com a participação da profa. Hélia Oliveira, que estava no Brasil.

De posse de uma versão preliminar do framework e dos materiais relativos à aula filmada, após E2, o grupo decidiu iniciar a estruturação do caso multimídia "Os colares" (E3). Nesse empreendimento, a partir de intencionalidades formativas, os membros do grupo definiram as seções que comporiam o caso multimídia, selecionaram os excertos em vídeos que seriam incluídos, elaboraram as questões que seriam propostas em cada uma das seções, negociaram que outros materiais/mídias seriam considerados, etc.

As negociações de significados e as reflexões compartilhadas pelo grupo foram selecionadas, transcritas, e articuladas com os referenciais teóricos adotados na pesquisa, principalmente no que se refere às dimensões do que consiste reconhecer e interpretar interações em sala de aula (ALSAWAIE; ALGHAZO, 2010; VAN ES; SHERIN, 2002, 2008), com o objetivo de analisar os aspectos da prática pedagógica considerados como ponto de enfoque pelo grupo no processo de elaboração do caso multimídia "Os colares".

\section{Apresentação dos resultados}

Apresentamos, a seguir, os aspectos da prática pedagógica, considerados como ponto de enfoque pelo Gepefopem na elaboração do caso multimídia "Os colares". Esses aspectos foram associados ao planejamento e à prática de um professor em uma aula na perspectiva do Ensino Exploratório.

\section{Aspectos da prática pedagógica associados ao planejamento}

Os aspectos da prática pedagógica, considerados pelo Gepefopem, na elaboração do caso multimídia "Os colares", associados ao planejamento foram:

1. Análise e escolha de tarefas matemáticas.

2. Elaboração de um inventário com possíveis resoluções dos alunos e estabelecimento de conexões entre elas.

Planejamento da discussão coletiva e da sistematização. Nos empreendimentos E1, E2 e E3, observamos a importância que os membros do Gepefopem atribuíram ao planejamento do professor para uma aula na perspectiva do Ensino Exploratório. A análise e escolha de tarefas matemáticas foi um dos aspectos considerados da ação do professor no planejamento de aulas na perspectiva do Ensino Exploratório. Nesse aspecto, estão envolvidos: o estudo do nível de demanda cognitiva da tarefa, os conhecimentos e as expectativas dos alunos, o modo como essa tarefa será implementada e o tratamento dos conhecimentos que ela pode mobilizar. Esses elementos podem interferir diretamente na concretização das intencionalidades do professor para a aula, ou seja, determinar com quais conceitos matemáticos ele deseja que seus alunos se envolvam e o que espera que eles aprendam. 
A análise dos níveis de demanda cognitiva de $\operatorname{tarefas}^{14}$ (CYRINO; JESUS, 2014; STEIN; SMITH, 2009) é um elemento que os membros do grupo reconheceram como potencial para aprendizagem dos alunos. O professor, tendo em conta os conhecimentos que deseja mobilizar, ao realizar esse tipo de análise, pode refletir a respeito da complexidade que a tarefa demanda, das características que ela possui quanto a seu enunciado e do modo proposto pelo professor e desenvolvido pelos alunos.

O grupo destacou que, no planejamento, após definir os objetivos da aula e a tarefa a ser trabalhada, o professor pode fazer uma previsão de possíveis resoluções dos alunos, constituindo um inventário de prováveis resoluções. Esse inventário permite ao professor antecipar e potencializar suas possíveis ações em sala de aula, as quais podem ser pensadas, a fim de prever articulação das resoluções entre si e possíveis relações entre essas resoluções e: os objetivos da aula, os diferentes tipos de registros, os possíveis questionamentos dos alunos.

Prever resoluções para a tarefa, reconhecer possíveis relações entre elas, articular diferentes tipos de registros e antecipar prováveis questionamentos a serem realizados para os alunos, representam formas de o professor configurar situações hipotéticas de ensino na perspectiva do Ensino Exploratório.

Um outro aspecto considerado pelo Gepefopem foi o Planejamento da discussão coletiva e da sistematização. Os membros do grupo destacaram que, a partir das possíveis resoluções pensadas previamente e de como será feito o monitoramento do trabalho dos alunos durante a resolução da tarefa, o professor pode planejar como organizar a discussão coletiva das resoluções (tendo em conta os registros, as justificativas, e os argumentos apresentados pelos alunos) e como articular essa discussão com a sistematização das aprendizagens dos alunos.

No Quadro 2, apresentamos os aspectos considerados pelo grupo e as falas dos membros que nos permitiram reconhecer tais aspectos.

Nas negociações de significados e nas reflexões compartilhadas pelos membros do Gepefopem, observamos a sua busca em reconhecer e interpretar como o planejamento de ações do professor pode promover interações em sala de aula, tendo em conta as três dimensões discutidas por Van Es e Sherin $(2002,2008)$ e por Alsawaie e Alghazo (2010), quais sejam: (i) identificar o que é importante ou digno de nota em uma situação de sala de aula; (ii) usar o que se sabe sobre o contexto para interpretar interações em sala de aula; (iii) fazer conexões entre as especificidades das interações em sala de aula e os princípios mais amplos de ensino e de aprendizagem.

A análise e a escolha de tarefas matemáticas, por exemplo, podem estar associadas a essas três dimensões, principalmente pelo fato de, na perspectiva do Ensino Exploratório, o professor levar em consideração o contexto no qual trabalha, as suas dificuldades, os conhecimentos de seus alunos, as dificuldades desses alunos, dentre outros. Essas três dimensões são fundamentais para o planejamento e a implementação de uma prática de ensino que reconheça a importância do papel das interações em sala de aula (VAN ES; SHERIN, 2002).

\footnotetext{
${ }^{14}$ Segundo Stein e Smith (2009), demanda cognitiva diz respeito a um tipo e nível de raciocínio exigido dos alunos para engajamento e resolução da tarefa com sucesso. 
Aspectos da prática pedagógica considerados na elaboração de um caso ...

Quadro 2. Aspectos da prática pedagógica associados ao planejamento

\begin{tabular}{|c|c|}
\hline $\begin{array}{l}\text { Aspectos da prática } \\
\text { pedagógica considerados } \\
\text { pelo grupo }\end{array}$ & $\begin{array}{l}\text { Negociações de significados ou reflexões } \\
\text { compartilhadas que evidenciam a consideração dos aspectos }\end{array}$ \\
\hline $\begin{array}{l}\text { Análise e escolha de tarefas } \\
\text { matemáticas }\end{array}$ & $\begin{array}{l}\text { "Eu também acho que a escolha das tarefas tem que ser de acordo com os } \\
\text { alunos que o professor tem" [Tânia, 12/04/2013]; "Isso. "Escolher tarefas } \\
\text { levando em consideração suas intençôes, o nivel de demanda cognitiva"” [Márcia, } \\
\text { 12/04/2013]; "O que o professor sabe sobre os alunos, no sentido de como } \\
\text { é que eles pensam, como é que eles agem... Quem são os alunos" [Tânia, } \\
\text { 12/04/2013]; "É o conbecimento dos alunos" [Paulo, 12/04/2013]; "[...] } \\
\text { a gente classifica as tarefas tendo em consideração quem são os alunos" [Marcia } \\
\text { Nagy, 12/04/2013]; "Como eles pensam, como é que eles se dedicam a um } \\
\text { trabalho em sala de aula" [Tânia, 12/04/2013]; "Não tem a ver só com o } \\
\text { conhecimento prévio, não é só isso. É como é que os alunos se envolvem com as } \\
\text { tarefas que o professor propõe" [Márcia, 12/04/2013]. }\end{array}$ \\
\hline $\begin{array}{l}\text { Elaboração de um inventário } \\
\text { com possíveis resoluções } \\
\text { dos alunos e estabelecimento } \\
\text { de conexões entre elas }\end{array}$ & $\begin{array}{l}\text { '[...] mas não é só antecipar por antecipar [possíveis resoluções], [um } \\
\text { professor antecipa] para que ele [um professor qualquer] possa perceber } \\
\text { algumas possíveis conexões que ele vai poder fazer no final, na fase de fazer } \\
\text { conexões com as ideias matemáticas” [Tânia, 12/04/2014]. }\end{array}$ \\
\hline $\begin{array}{l}\text { Planejamento da discussão } \\
\text { coletiva e da sistematização }\end{array}$ & $\begin{array}{l}\text { 'Porque o foco do 'monitorar' segundo o texto [STEIN et al., 2008] é } \\
\text { monitorar as ideias matemáticas e já planejar, de certa forma, o que vai ser } \\
\text { apresentado [na discussão e na sistematização]" [Loreni, 25/04/2013]. }\end{array}$ \\
\hline
\end{tabular}

Fonte: elaborado pelos autores.

Relacionamos a elaboração de um inventário com possíveis resoluções dos alunos e o estabelecimento de conexões entre elas com as duas primeiras dimensões do que consiste reconhecer e interpretar interações em sala de aula. Ao inventariar possíveis resoluções de tarefas, o professor pode configurar uma situação hipotética de ensino na perspectiva do Ensino Exploratório e, a partir de todas as resoluções antecipadas, identificar as que selecionaria para discussão coletiva e em que sequência elas seriam apresentadas, caso fossem mobilizadas em sala de aula. A identificação de tais resoluções remete à primeira dimensão, uma vez que, ainda que hipoteticamente, o professor identifica algo digno de nota em uma situação de ensino. Para que o professor estabeleça conexão entre as resoluções, faz-se necessário que ele as interprete, usando o que sabe do contexto (segunda dimensão).

O planejamento da discussão coletiva e da sistematização pode estar associado às duas primeiras dimensões, principalmente pelo fato de, na ação de monitorar, o professor identificar nas produções dos alunos elementos que se relacionam ao seu objetivo de ensino, o que é fundamental na perspectiva do Ensino Exploratório (primeira dimensão). A partir dessa identificação, cabe ao professor planejar como organizar a discussão coletiva e a sistematização. Tal planejamento pode ser desenvolvido por meio da interpretação dos elementos que o professor identifica nas produções dos alunos (segunda dimensão). 


\section{Prática do professor em uma aula na perspectiva do Ensino Exploratório}

No que se refere à prática do professor em uma aula na perspectiva do Ensino Exploratório, o Gepefopem discutiu os seguintes aspectos na elaboração do caso multimídia "Os colares":

Reconhecimento da necessidade de realizar algum tipo de intervenção.

1. Reconhecimento dos alunos como produtores de conhecimento.

2. Reconhecimento de diferentes resoluções para uma mesma tarefa.

3. Identificação das resoluções dos alunos.

4. Intepretação das resoluções dos alunos.

5. Solicitação de justificativas e valorização dos argumentos dos alunos.

6. Busca de compreensão das produções dos alunos.

7. Seleção e sequenciamento das resoluções dos alunos, as quais deseja discutir.

8. Estabelecimento de relações entre as produções dos alunos e as representações matemáticas formalizadas.

9. Proposição de questionamentos para promover interações em sala de aula.

10. Estabelecimento de relação entre o que acontece em sala de aula e o que foi planejado.

A partir do trabalho com uma tarefa na perspectiva do Ensino Exploratório, os alunos podem mobilizar suas resoluções, representadas por meio de seus registros escritos ou falas. Os membros do Gepefopem consideraram diferentes ações do professor diante dessa mobilização. O professor identifica as resoluções (aspecto 4), no momento do desenvolvimento da tarefa, já pensando em uma possível seleção e sequenciamento para discussão coletiva (aspecto 8), para imaginar como seria feita a discussão.

Os membros do Gepefopem consideraram que, no planejamento, o professor estabelece objetivos de ensino e define quais ideias, conceitos ou conteúdos matemáticos que deseja sistematizar, ou seja, estabelece suas intenções. No momento em que o professor monitora o trabalho dos alunos, a partir das resoluções que identificou (aspecto 4), ele avalia quais resoluções são potenciais para discutir e sistematizar, tendo em conta as suas expectativas quanto à aprendizagem dos alunos. Assim, ele pode interpretar as resoluções que os alunos mobilizam (aspecto 5) e relacioná-las com suas intenções, com seus objetivos de ensino, ou seja, com parte de seu planejamento (aspecto 11).

Interpretamos, a partir das considerações dos membros do Gepefopem, que é papel do professor reconhecer que diferentes resoluções (aspecto 3) resolvem a tarefa e, sendo assim, explicitar aos alunos as características de cada uma delas, no sentido de possibilitar que eles compreendam que diferentes resoluções podem resolver uma mesma tarefa.

Diante das resoluções que os alunos mobilizam, os membros do Gepefopem apontaram outras ações relativas à prática pedagógica assumidas como importantes na perspectiva do Ensino Exploratório, como avaliar quando é necessário realizar intervenções (aspecto 1) e fazer questionamentos (aspecto 10). Nessa dimensão, a avaliação do quando e do tipo de intervenção a ser realizada pelo professor é constante. Cabe ao professor entender quando ele deve deixar os alunos mais "livres", quando deve direcionar mais seus questionamentos, quando deve solicitar justificações (aspecto 6). Além disso, diferentes intencionalidades podem 
Aspectos da prática pedagógica considerados na elaboração de um caso ...

ser consideradas durante esse processo, nomeadamente: quando realizar essa intervenção, como promover interação entre os alunos, quando solicitar justificativas, como valorizar os argumentos dos alunos, como fazer para compreender as produções dos alunos (além da interpretação das resoluções) (aspecto 7), quando orientar o desenvolvimento de uma estratégia por partes de alunos que apresentam dificuldades, etc.

Ainda com relação às resoluções que os alunos mobilizam em uma aula na perspectiva do Ensino Exploratório, os membros do Gepefopem pontuaram um aspecto específico relativo às ações do professor: relacionar as resoluções e as representações que os alunos mobilizam com as representações matemáticas formalizadas (aspecto 9). Os participantes consideraram esse aspecto, principalmente, pela importância em relacionar as produções dos alunos com a "matemática escolar institucionalizada", formalizada nos livros e nos manuais pedagógicos.

Alguns membros relatavam que, em aulas pautadas em enfoques alternativos de ensino, existe uma interpretação que considera que essas representações matemáticas formalizadas sejam apresentadas isoladamente, sem o compromisso de relacioná-las com as resoluções dos alunos. De acordo com o grupo, no Ensino Exploratório, as ideias, os conceitos ou os conteúdos matemáticos que o professor deseja sistematizar devem ser associados às produções dos alunos.

Foi atribuída pelo grupo uma importância significativa à consideração dos alunos como produtores de conhecimento, como seres que aprendem (LINS, 1999). Considerar "onde os alunos se encontram" do ponto de vista cognitivo, a fim de reconhecer os conhecimentos que eles já possuem e de novos que podem constituir e organizar suas ações a partir dessa consideração, são ações do professor, valorizadas pelo grupo na elaboração do caso multimídia “Os colares". No Quadro 3 apresentamos os aspectos da prática pedagógica considerados pelo grupo e as negociações de significados dos membros que dizem respeito a tais aspectos.

Quadro 3. Aspectos da prática pedagógica associados à prática do professor

\begin{tabular}{|l|l|}
\hline \multicolumn{1}{|c|}{$\begin{array}{c}\text { Aspectos da } \\
\text { prática pedagógica } \\
\text { considerados pelo grupo }\end{array}$} & $\begin{array}{c}\text { Negociações de significados ou reflexões compartilhadas que } \\
\text { evidenciam a consideração dos aspectos }\end{array}$ \\
\hline $\begin{array}{l}\text { 1. Reconhecimento da } \\
\text { necessidade de realizar } \\
\text { algum tipo de intervenção }\end{array}$ & $\begin{array}{l}\text { Percebe-se que tipo de estratégia [é utilizada pelos alunos] e decide se é } \\
\text { necessário fazer algumas intervençóes" [Tânia, 26/04/2013]. }\end{array}$ \\
\hline $\begin{array}{l}\text { 2. Reconhecimento dos } \\
\text { alunos como produtores de } \\
\text { conhecimento }\end{array}$ & $\begin{array}{l}\text { "T...] o professor consegue ver onde é que os alunos estão" (Tânia, 26/04/2013); } \\
\text { "...] identificar onde os alunos estão matematicamente no contexto daquele } \\
\text { conhecimento matemático" [Tânia, 26/04/2013]; "Tem que ir onde o aluno } \\
\text { está, identificar onde esse aluno está [do ponto de vista cognitivo]" [Márcia, } \\
\text { 26/04/2013]. }\end{array}$ \\
\hline $\begin{array}{l}\text { 3. Reconhecimento de } \\
\text { diferentes resoluções para } \\
\text { uma mesma tarefa. }\end{array}$ & $\begin{array}{l}\text { "Salientarpara os alunos a possibilidade de diferentes resoluçôes para o } \\
\text { problema" [Everton, 25/04/2014]. }\end{array}$ \\
\hline
\end{tabular}


Quadro 3. continuação

\begin{tabular}{|c|c|}
\hline $\begin{array}{c}\text { Aspectos da } \\
\text { prática pedagógica } \\
\text { considerados pelo grupo }\end{array}$ & $\begin{array}{l}\text { Negociações de significados ou reflexões compartilhadas que } \\
\text { evidenciam a consideração dos aspectos }\end{array}$ \\
\hline $\begin{array}{l}\text { 4. Identificação das } \\
\text { resoluções dos alunos }\end{array}$ & $\begin{array}{l}\text { "Identificar as estratégias dos alunos e de algum modo, também, identificar a } \\
\text { intervenção da professora frente à essas estratégias" [Everton, 06/02/2014]; } \\
\text { "ele identifica as estratégias utilizadas pelos alunos e como a professora se } \\
\text { posiciona diante dessas estratégias" [Márcia, 06/02/2014]; "Qual(is) } \\
\text { estratégias é(são) utilizadas pelos alunos?” [Laís, 06/02/2014]; "Não, não } \\
\text { é identificar. Mantém a questão das estratégias e como é que eles justificam as } \\
\text { estratégias que eles escolheram. Não é isso? Não é essa intenção?” [Márcia, } \\
06 / 02 / 2014]\end{array}$ \\
\hline $\begin{array}{l}\text { 5. Interpretação das } \\
\text { resoluções dos alunos }\end{array}$ & 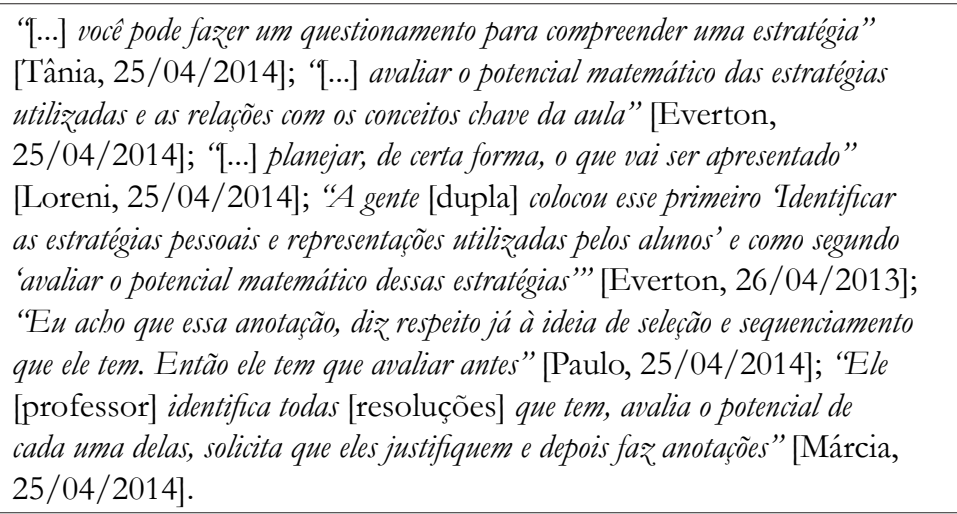 \\
\hline $\begin{array}{l}\text { 6. Solicitação de } \\
\text { justificativas e valorização } \\
\text { dos argumentos dos alunos }\end{array}$ & $\begin{array}{l}\text { "Eu acho que era uma coisa no sentido assim: eu não posso validar, mas eu tenho } \\
\text { que minimamente garantir que o aluno compreendeu. Isso vai ser explicitado } \\
\text { a partir das justificativas que eles apresentam para estratégias e procedimentos } \\
\text { que eles utilizam para resolução. Penso que seria algo nesse sentido" [Everton } \\
02 / 06 / 2014] \text {; "[...] é uma estratégia que ela [professora Cristina] utiliza } \\
\text { para observar se os alunos compreenderam de fato, ao pedir para eles justificarem" } \\
\text { [Paulo, 02/06/2014]; "É uma questão relacionada à interaşão, não é? O } \\
\text { aluno ao justificar leva a professora a perceber que eles compreendem" [Hélia, } \\
02 / 06 / 2014] \text {; "Ele [professor] identifica todas [resoluções] que tem, } \\
\text { avalia o potencial de cada uma delas, solicita que eles justifiquem, valoriza suas } \\
\text { produçoes, e depois faz anotaçôes".[Márcia, 25/04/2014]. }\end{array}$ \\
\hline $\begin{array}{l}\text { 7. Busca da compreensão } \\
\text { das produções dos alunos }\end{array}$ & $\begin{array}{l}\text { "É entender o que ele explica e buscar entender o significado atribuido pelo aluno } \\
\text { a uma determinada coisa" [Márcia, 26/04/2013]; "Eu não sei se está claro } \\
\text { em algum desses itens, se é nesse momento que o professor entende o que os alunos } \\
\text { estão fazendo" [Loreni, 25/04/2014] "Ele solicita justificaşöes para poder } \\
\text { entender" [Márcia, 25/04/2014]. }\end{array}$ \\
\hline $\begin{array}{l}\text { 8. Seleção e sequenciamento } \\
\text { das resoluções dos alunos, } \\
\text { as quais deseja discutir }\end{array}$ & $\begin{array}{l}\text { "Das que ele quer, ele seleciona e anota" [Paulo, 25/04/2014]; "Eu sabia as } \\
\text { cinco que tinha, eu sabia a ordem, mas eu não sabia com quem estava” [Loreni, } \\
\text { 25/04/2014]; "Eu acho que essa anotação, dir respeito já à ideia de seleção e } \\
\text { sequenciamento. Então ele tem que avaliar e anotar" [Paulo, 25/04/2014]. }\end{array}$ \\
\hline
\end{tabular}


Aspectos da prática pedagógica considerados na elaboração de um caso ...

Quadro 3. continuação

\begin{tabular}{|c|c|}
\hline $\begin{array}{c}\text { Aspectos da } \\
\text { prática pedagógica } \\
\text { considerados pelo grupo }\end{array}$ & $\begin{array}{c}\text { Negociações de significados ou reflexões compartilhadas que } \\
\text { evidenciam a consideração dos aspectos }\end{array}$ \\
\hline $\begin{array}{l}\text { 9. Estabelecimento de relações } \\
\text { entre as produções dos } \\
\text { alunos e as representações } \\
\text { matemáticas formalizadas }\end{array}$ & $\begin{array}{l}\text { "Relacionar as ideias e procedimentos presentes nas estratégias dos alunos com as } \\
\text { representaçöes matemáticas formalizadas ou sistematizadas" [Tânia, 24/05/2013]; } \\
\text { "Eu observo muito no estágio, que os alunos [futuros professores] discutem } \\
\text { as resoluçōes dos alunos, mas não estabelecem relaçoes entre essas produções e a } \\
\text { sistematização" [Márcia, 24/05/2013]. }\end{array}$ \\
\hline $\begin{array}{l}\text { 10. Proposição de } \\
\text { questionamentos }\end{array}$ & $\begin{array}{l}\text { "[...] existem vários momentos em que o professor pode fazer questionamentos. } \\
\text { Porque, dependendo da interpretação, você pode fazer um questionamento para } \\
\text { compreender uma estratégia, para que o aluno explicite melhor o que ele está } \\
\text { pensando. Você pode fazer também questionamentos. Às vezes o aluno iniciou } \\
\text { uma estratégia, mas você pode fazer [questionamentos] para encaminhar } \\
\text { outras" [Tânia, 25/04/2014]. }\end{array}$ \\
\hline $\begin{array}{l}\text { 11. Estabelecimento de } \\
\text { relação entre o que acontece } \\
\text { em sala de aula e o que foi } \\
\text { planejado }\end{array}$ & $\begin{array}{l}\text { "A professora conseguin atingir os objetivos indicados no plano de aula?" [Hélia, } \\
06 / 02 / 2014] \text {. }\end{array}$ \\
\hline
\end{tabular}

Fonte: elaborado pelos autores.

Os aspectos 1, 2, 3, 4 e 8, remetem à primeira dimensão do que consiste reconhecer e interpretar interações em sala de aula - identificar o que é importante ou digno de nota em uma situação de sala de aula (ALSAWAIE; ALGHAZO, 2010; VAN ES; SHERIN, 2002, 2008) -, principalmente por possibilitar que o professor considere os diferentes elementos dignos de nota em situações de ensino, como: realização de algum tipo de intervenção, observação dos alunos como produtores de conhecimento, diferentes resoluções para uma mesma tarefa, identificação ou seleção de resoluções mobilizadas pelos alunos com características específicas, que se relacionam ou não ao seu objetivos.

Os aspectos 1, 5, 6, 7 e 10, remetem à segunda dimensão do que consiste reconhecer e interpretar interações em sala de aula, - usar o que se sabe sobre o contexto para interpretar interações em sala de aula (ALSAWAIE; ALGHAZO, 2010; VAN ES; SHERIN, 2002, 2008) -, principalmente por considerar elementos que podem ser alcançados a partir da interpretação de interações em sala de aula, tais como: avaliação de quando é necessário realizar intervenções (solicitação de justificativas e proposição de questionamentos), compreensão das produções dos alunos, dentre outros.

Já os aspectos 9 e 11 se relacionam à dimensão (iii) - fazer conexões entre as especificidades das interações em sala de aula e os princípios mais amplos de ensino e de aprendizagem (ALSAWAIE; ALGHAZO, 2010; VAN ES; SHERIN, 2002, 2008) -, porque dizem respeito às relações que os professores podem estabelecer entre produções de sala de aula e aspectos mais gerais (representações matemáticas formalizadas e o planejamento). 


\section{Algumas considerações}

Os aspectos da prática pedagógica, considerados pelo Gepefopem na elaboração do caso multimídia, revelam as suas expectativas de a exploração desse caso na formação de professores que ensinam Matemática ser uma significativa oportunidade de desenvolvimento da identidade profissional. "Entendemos a identidade profissional de professores como um conjunto de crenças/concepções interconectadas e de conhecimentos a respeito do seu ofício, associados à autonomia (sentido de vulnerabilidade e de agência) e ao compromisso político" (CYRINO, 2016b, p. 168, grifos do autor).

O fato de o caso multimídia tomar como ponto de partida situações reais em sala de aula na perspectiva do Ensino Exploratório indica sua potencialidade quanto à legitimação de um contexto formativo para levar os professores em formação a considerarem que é possível realizar em sala de aula um trabalho alternativo ao ensino diretivo ou expositivo (centrado na transmissão de conteúdos). O Ensino Exploratório nas aulas de Matemática enquadra-se em uma perspectiva mais ampla Inquiry-based Mathematics Education, que privilegia inquiry, colaboração, comunicação e reflexão (CYRINO; OLIVEIRA, 2016).

Nessa direção, a exploração desses aspectos da prática pedagógica, considerados pelo grupo em contextos de formação (inicial e continuada), pode desencadear, nos (futuros) professores em formação, um (re)pensar a respeito de suas crenças, concepções, atitudes e conhecimentos sobre seu ofício, resultando no desejo de buscar novos horizontes e conhecer novas possibilidades de trabalho em sala de aula. Ao associar a identificação, a interpretação e a análise dos aspectos da prática pedagógica, apresentados neste trabalho, à compreensão de si mesmo, como (futuro) professor, ele terá a oportunidade de reconhecer e refletir sobre sua importância como principal organizador e gestor no processo de ensino e um dos agentes do processo de aprendizagem dos alunos.

Defendemos uma formação de professores que privilegie o desenvolvimento da autonomia e do compromisso político dos (futuros) professores, a partir de seus conhecimentos e experiências a respeito da sua (futura) profissão e, por conseguinte, o desenvolvimento de sua identidade profissional.

\section{Agradecimentos}

Agradecemos o apoio financeiro do Conselho Nacional de Desenvolvimento Científico e Tecnológico (CNPq) e da Fundação Araucária.

\section{Referências}

ALSAWAIE, O.; ALGHAZO, I. The effect of video-based approach on prospective teachers' ability to analyze mathematics teaching. Journal of Mathematics Teacher Education, New York, v. 3, n. 3, p. 223-241, 2010.

BATES, A. W. Technology, e-learning and distance education. 2. ed. London: Routledge Falmer, 2005. 
Aspectos da prática pedagógica considerados na elaboração de um caso ...

CANAVARRO, A. P. Ensino exploratório da matemática: práticas e desafios. Educação e Matemática, Lisboa, v. 115, n. 1, p. 11-17, 2011.

CHAPMAN, O. Mathematics teachers' learning through inquiry. Sisyphus, Lisboa, v. 1, n. 3, p. 122-150, 2013.

CYRINO, M. C. C. T. Comunidades de prática de professores como espaço de investigação sobre a formação de professores de matemática. In: BATISTA, I. L.; SALVI, R. F. (Org.). Pósgraduação em ensino de ciências e educação matemática: um perfil de pesquisas. Londrina: EDUEL, 2009. p. 95-110.

Mathematics teachers' professional identity development in communities of practice: reifications of proportional reasoning teaching. Bolema: boletim de educação matemática, Rio Claro, v. 30, p. 165-187, 2016b.

. (Org). Recurso multimídia para a formação de professores que ensinam matemática: elaboração e perspectivas. Londrina: EDUEL, 2016a.

CYRINO, M. C. C. T.; CALDEIRA, J. S. Processos de negociação de significados sobre pensamento algébrico em uma comunidade de prática de formação inicial de professores de matemática. Investigações em Ensino de Ciências, Porto Alegre, v. 16, n. 3, p. 373-401, 2011.

CYRINO, M. C. C. T.; JESUS, C. C. Análise de tarefas matemáticas em uma proposta de formação continuada de professoras que ensinam matemática. Ciência \& Educação, Bauru, v. 20, p. 751-764, 2014.

CYRINO, M. C. C. T.; OLIVEIRA, H. M. Ensino exploratório e os casos multimídia na formação de professores que ensinam matemática. In: CYRINO, M. C. C. T. (Org). Recurso multimídia para a formação de professores que ensinam matemática: elaboração e perspectivas. Londrina: EDUEL, 2016. p. 19-32.

CYRINO, M. C. C. T.; TEIXEIRA, B. R. O ensino exploratório e a elaboração de um framework para os casos multimídia. In: CYRINO, M. C. C. T. (Org). Recurso multimídia para a formação de professores que ensinam matemática: elaboração e perspectivas. Londrina: EDUEL, 2016. p. 81- 99.

DEWEY, J. How we think. New York: Dover, 1997.

GARCIA, T. M. R. Identidade profissional de professor de matemática em uma comunidade de prática. 2014. 161 f. Tese (Doutorado em Ensino de Ciências e Educação Matemática) - Universidade Estadual de Londrina, Londrina, 2014.

KRAINER, K. Teams, communities \& networks. Journal of Mathematics Teacher Education, Dordrecht, v. 6, n. 2, p. 93-105, 2003.

LINS, R. C. Por que discutir teoria do conhecimento é relevante para a educação matemática. In: BICUDO, M. A. V. (Org.). Pesquisa em educação matemática: concepções e perspectivas. São Paulo: Editora da UNESP, 1999. p. 75-94. 
NAGY, M. C.; CYRINO, M. C. C. T. Aprendizagens de professoras que ensinam matemática em uma comunidade de prática. Revista FAEEBA, Salvador, v. 23, p. 149-163, 2014.

NATIONAL COUNCIL OF TEACHERS OF MATHEMATICS. Principles and standards for school mathematics. Reston, 2000.

OLIVEIRA, H. M.; MENEZES, L.; CANAVARRO, A. P. Conceptualizando o ensino exploratório da matemática: contributos da prática de uma professora do $3 .^{\circ}$ ciclo para a elaboração de um quadro de referência. Quadrante, Lisboa, v. 22, n. 2, p. 29-53, 2013.

OLIVEIRA, H. M.; CYRINO, M. C. C. T. Developing knowledge about inquiry-based teaching through analysis of a multimedia case: a study with prospective mathematics teachers. Sisyphus, Lisboa, v. 1, n. 3, p. 214-245, 2013.

RODRIGUES, P. H. Práticas de um grupo de estudos e pesquisa na elaboração de um recurso multimídia para a formação de professores que ensinam matemática. 2015. 228 f. Dissertação (Mestrado em Ensino de Ciências e Educação Matemática) - Universidade Estadual de Londrina, Londrina, 2015.

RODRIGUES, P. H.et al. A mídia vídeo na formação de professores que ensinam Matemática: análises de pesquisas brasileiras. Nuances: estudos sobre educação, Presidente Prudente, v. 25, n. 2, p. 148-169, 2014.

SANTAGATA, R.; GUARINO, J. Using video to teach future teachers to learn from teaching. ZDM: the international journal of mathematics education, Hamburg, v. 43, n. 1, p. $133-145,2011$.

SCHON, D. Educando o profissional reflexivo: um novo design para o ensino e aprendizagem. Porto Alegre: Artes Médicas Sul, 2000.

STEIN, M. K.; SMITH, M. S. Tarefas matemáticas como quadro para a reflexão: da investigação à prática. Educação e Matemática, Lisboa, v.105, n. 1, p. 22-28, 2009.

STEIN, M. et al. Orchestrating productive mathematical discussions: five practices for helping teachers move beyond show and tell. Mathematical Thinking and Learning, Philadelphia, v. 10, n. 4, p. 313-340, 2008.

VAN ES, E. A.; SHERIN, M. G. Learning to notice: scaffolding new teachers' interpretations of classroom interactions. Journal of Technology and Teacher Education, Norfolk, v. 10, n. 4, p. 571-596, 2002.

VAN ES, E. A.; SHERIN, M. G. Mathematics teachers "learning to notice" in the context of a video club. Teaching and Teacher Education, Kidlington, v. 24, p. 244-276, 2008.

WELLS, G. Dialogic inquiry: towards a sociocultural practice and theory of education. Cambridge: Cambridge University Press, 2004.

WENGER, E.; MCDERMOTT, R.; SNYDER, W. M. Cultivating communities of practice. Boston: Harvard Business School Press, 2002. 
Aspectos da prática pedagógica considerados na elaboração de um caso ...

Artigo recebido em 02/09/2016. Aceito em 25/11/2016.

Endereço para contato: UEL, Departamento de Matemática, Rodovia Celso Garcia Cid - Pr 445 Km 380, Londrina, PR, CEP 86057-970, Brasil. 